\section{Ethical Lingua}

Journal of Language Teaching and Literature

ISSN 2355-3448 (Print)

ISSN 2540-9190 (Online)

Volume 4, Number 1, February 2017

pp. $52-60$.

\title{
How to Write an English Research Introduction?
}

\author{
Warsidi \\ warsidi_widi@yahoo.com
}

Universitas Islam Makassar, Indonesia

\author{
Submitted : 22 January 2017, Accepted: 7 February 2017 \\ URL : : http://journal.uncp.ac.id/index.php/ethicallingua/article/view/348
}

\begin{abstract}
This study is librarian analysis which collects the data from books and journal articles. Those articles and books chapters discuss about introductions in terms of their generic structures. The data collections were applied by reading, taking notes for their generic structures, and analyzing them in term of their generic structure models. Then, the data were reported using qualitative approach by describing their patterns. The results showed that there two big categories for their models, involving pattern models and free models. Pattern models dominated in this study because they have been applied seven experts, while free models have been applied by only two people. Therefore, this study suggests that if the journal, which you direct to publish your articles, doesn't have pattern, you are recommended to apply the patterns as the following: CARS model from Swales, IPS model from Adnan (2011), Slatcher \& Pennebaker, and Ball \& Vincent.
\end{abstract}

Keywords: research article, research introduction, library analysis

\section{Introduction}

Writing an English research introduction is rather complicated as the writer looks various errors in students writing, more particularly when writing their research proposal. Those errors, as the writer's attention to them, involve punctuation, capitalization, grammar, content, appropriate vocabularies and even in writing sentences, they sometimes form incompletely. Those writing analysis categories have been applied by Warsidi (2013) when he conducted research on essay writing. The majority students don't apply those categories in their academic writing because still many students write without verb in their sentences. They can't diverse which sentence is suitable for, and so on. They always write in very Indonesian literal translation such as in Pasongli (2016): 
"there are several cultures which held readily over yet, essentially are funeral ceremony, that is called by Rambu' Solo and the custom which associated with thankfulness ritual, as well as known by Rambu Tuka", (p.2).

Moreover, when talking to the students, some of them actually already know the concepts of their introduction, but they get difficulties to write what the ideas in their mind. The ways to write and the grammars are very complicated to show ideally to the readers. Choosing appropriate vocabularies in writing are also obstacles for them. In other hands, it is not only happened in Indonesia, but also in other countries as Van De Weghe (2007) stated when observing his students, that they can read all texts in the books, but they can't get the points of the texts. It means that vocabulary is also obstacles for his students.

Beside attention to those errors, English research introduction has different styles with the eastern country, English research introduction. For example Swale \& Feak in Hartley (2008) stated that English research introduction is divided in three 'moves'. As the obligatory in move one, previous researches are introduced and reviewed. Then, the previous research weaknesses are analyzed to find their gap. After that, stating the urgent of your research is also very well planned to attract your readers (p.41).

For those problems, therefore the research article introduction should follow some rules for well received by the readers, more particularly for internationally published. It may have some patterns. Writing English research introductions had been also conducted by many experts and practitioners such as Swale in Hartley (2008; 41), Slatcher \& Pennebaker's introduction as cited by Hartley (2008; 42), Jogthong (2001), Adnan (2011), Jalilifar (2010), Al-Qahtani (2006), Tulu (2009), Ball and Vincent as cited by Woods (1999), Kalandadze (2007), etc. Those may be well applied in their environments, but in other sides, we should investigate the needs for our environments. This article will investigate the writing styles in the introduction stage. It means that how to manage the ideas in the introduction, such as its generic structures, is the focus of this study to find the ideal research article introduction for research paper.

\section{The Scopes of the Study}

This study focuses on analyzing the some research article introduction models or styles, applied by Swale in Hartley (2008: 41), Slatcher \& Pennebaker's introduction as cited by Hartley (2008; 42), Jogthong (2001), Adnan (2011), Jalilifar (2010), Al-Qahtani (2006), Tulu (2009), Ball and Vincent as cited by Woods (1999), and Kalandadze (2007). The analysis styles are on their generic structures. Therefore, it limits the study on the styles in term of their generic structures. 


\section{Reviewing Research Introduction Studies}

This article analyses some related academic writing focusing on research article introduction. The writer collects and reads various academic writing books and journal articles, more specifically on research introductions. The books and articles about research article introductions are analyzed and discussed in term of their writing styles.

\section{Research Introduction Based on Swales}

Research article introduction applied by Swales may divers to others. In his application, writing research introduction, Swale in Hartley' (2008) stated as the following; 1). Introducing the area of our research and reviewing other related researches. 2). Understanding the weaknesses of our review as a gap, questioning their research. 3). Offering our research as complete-ness by saying the purposes of our research (p. 41). Moreover, Hartley claimed most RAls applied this model. Therefore, this model, according to him, may be an ideal model for writing RAls.

\section{Research Introduction on Slatcher and Pennebaker}

Slatcher and Pennebaker's introduction as cited by Hartley $(2008 ; 42)$ also have 'five paragraphs', as follows:

a. Paragraph 1 and 2 describe research areas with various key phrases such as: 'Researchers are now planning, ... previous findings suggest that...,

b. Determining a gap in paragraph 2 and 4, by saying: 'Although previous studies have discussed about, ... but none statements states...', 'a crucial connector is ...', 'There are many methods to measure ...', 'The use of emotional words may be particularly relevant ...', 'One way is to analyze the texts used in instant messaging ...'

c. Paragraph 5 is the conclusion paragraph in the introduction by placing the gap. It may say: 'In the present study we need to investigate the social effects of expressive writing ...', 'Three statements were evaluated. First ...'

\section{RAls Developed by Adnan}

Create a Research Space (CARS) from Swales and PJP from Safnil were analyzed by Adnan (2011) in his Ideal-Problem-Solution (IPS) of Research Article Introductions (RAls). In the results of his research that the possible problems lie in the inappropriate rhetorical patterns found in the introductions of Indonesian research articles, but he only examined the introductions and citations.

He compared the Indonesian research article introductions which are dominant inconsistent rhetorical structure and English research article introductions that apply CARS models. He used CARS model because it is 
identified as the acceptable model in the international article study. In his analysis, he stated that Indonesian academics have not applied CARS models, which then this model has been claimed used in English research article introduction internationally.

As a result, Adnan (2011) designed solution for the Ideal Problem Solution (IPS) model to be applied in the Research Article Introductions (RAls). The IPS model designed by Adnan (2011, p; 87) can be looked as follows:

$\begin{array}{ll}\text { Move 1: Describing the 'Ideal' and the conditions to achieve it } \\ \text { Strategy A } & \text { Referring to expert views, and/or } \\ \text { Strategy B } & \text { Presenting own view, and/or } \\ \text { Strategy C } & \text { Referring to a government document(s) or official statement(s) } \\ \text { Move 2: } & \text { Justifying the study } \\ \text { Strategy A } & \text { Raising a problem by contrasting the ideal with the existing situation, and } \\ \text { Strategy B } & \text { Announcing the benefits of the study, and/or } \\ \text { Strategy C } & \text { Stating a gap in the literature, and/or } \\ \text { Strategy D } & \text { Stressing the need to conduct the study, and/or } \\ \text { Strategy E } & \text { Presenting an idea(s) to realize the ideal } \\ \text { Move 3: } & \text { Describing the study } \\ \text { Strategy A1 } & \text { Stating the object of the study, and/or } \\ \text { Strategy A2 } & \text { Outlining the purpose(s), and/or } \\ \text { Strategy A3 } & \text { Presenting the study question(s) } \\ \text { Strategy B } & \text { Explaining the theoretical framework with references }\end{array}$

\section{Research Introduction Applied by Jogthong}

Research introduction applied by Jogthong (2001) also used Create a Research Space (CARS) models designed by Swales. He conducted the research in Thai. In his analysis, from 40 articles that he analyzed, many writers didn't apply the CARS models. He claimed that they used inconsistent models. The results showed that their articles were stiff and less acceptable. It may be caused by their culture.

\section{Research Introductions Analyzed by Jalilifar}

After Jalilifar (2010) analyzed the 20 local Research Article Introductions (RAls) and 20 international research introductions, he found that the differences among them are the generic organization. Those 40 journal articles both locally and internationally published are social sciences, including English for Specific Purposes (ESP), Discourse Analysis (DA), and English General Purposes (EGP). The instruments used in the study are also CARS model. Since the local researchers find the difficulties in term organization, it may cause ineffective information. Therefore, this study interrupts to follow the instruction to make clear 
organization and effective knowledge (p. 52-53).

In the similar study, Al-Qahtani (2006) also conducted study of comparison on Arabic and English research introductions. He studied in the rhetoric aspects. It meant that his study also as similar as Jalilifar, but they have different objects. Their instruments to analyze the data are also as same as another, using CARS models. CARS models are becoming familiar in the study of generic structures.

\section{Research Introduction in Tulu}

The proposal introduction as stated by Tulu (2009) would be better by stating strictly on the subject research. Your research materials should be clearly informed because your readers may not be familiar with your research. The research must give enough backgrounds to ease the readers and offers the solution related to what being discussed. The main thing, your introduction also should consider your reviewers about their interest impression of the research writing. Also, reviewing the subject in your research is also desirable. The information are needed to inform clearly what the research problem, to detail your own competence in the field; and to clarify why it needs to be researched as detail, because the reviewer may also want to know who has researched previous your related subjects ( $p$; 46-47).

\section{Research introduction stated by Ball and Vincent}

Ball and Vincent as cited by Woods (1999) said that introduction may use quotation directly in the first sentence in the introduction stage, but it is not surely needed. Here, quotations used in the introduction are just to contrast or to compare the ideas about disagreement between the quotation statement and the writer's thought. Furthermore, the previous literatures can be added, developed, or evaluated as a gap of our writing. Then, they usually discuss the previous papers of related topics and examined their literature in term of content, while they focus more on its structure and functions. They also indicate that how their data are analyzed. The last paragraph of the Introduction is short conclusion about what they are going to do, and then making research questions, objectives of the study, scope of research, and significances of the research $(p ; 31)$.

\section{Research Introduction Based on Kalandadze}

Kalandadze (2007) argued that the aims in writing introduction are to inform the background of our research about what the context and how the model is. If the model is usual, it may be uninteresting. According to him, actually there is no permanent pattern about the style of our opening paragraph. It depends on our ability to design clearly and truly on the materials which we discuss. At least, still according to him, there are four strategies that may be applied in writing research introduction: first, design the research question in the current issues, next provide 
short and suitable backgrounds, place the research questions in the central stage, refer to the most relevant and representative publications, such books or journal articles (p. 73).

Especially for introduction part, he also suggested at least eight 'elements', but not the generic structures, which involved:

$1^{\text {st }}$, mentioning the problems because it is often as the aims of research.

$2^{\text {nd }}$, preparing which the area that will be researched.

$3^{\text {rd }}$, arguing the reasons why we conduct this research and what the urgent thing.

$4^{\text {th }}$, explaining what the focused problems that will be research.

$5^{\text {th }}$, understanding what the variables and mentioning the problems that will be analyzed.

$6^{\text {th }}$, if any, mention your hypothesis

$7^{\text {th }}$, identifying our research scopes

$8^{\text {th }}$, giving key definition; but it is not obligation.

\section{Methodology}

The writer reads several introduction styles presented by Swale in Hartley (2008; 41), Slatcher \& Pennebaker's introduction as cited by Hartley (2008; 42), Jogthong (2001), Adnan (2011), Jalilifar (2010), Al-Qahtani (2006), Tulu (2009), Ball and Vincent as cited by Woods (1999), Kalandadze (2007), etc. Then, all explaining the introductions are read continuously, comprehended, para-phrased, and then analyzed. In this study, generic structures or informational structures were the central for the analysis of RA introductions to see their patterns.

This study applies a qualitative approach on their generic structures that follow several steps:

1. The first step was conducting a fast reading

2. The second stage of analysis concentrated on the introductions, reading analysis,

3. Analyzing and making notes of their generic structure patterns or styles, Making reports of the analysis reports using qualitative approachs.

\section{Discussion}

This study has differences with others which they may analyze 40 articles using CARS model or other models, while this study is finding models applied by some theorist. However, this is not analyzing articles using particular models as measurements, but it tends more on what models or what styles have been applied by many authors in writing theirs.

This stage is the discussion part which explains the models applied by experts in the above writing. Because too many models applied in their RAls, this study will only divers on some parts of models to narrowing the discussion. Based 
on findings, the experts who were quoted above argued several differences. In this case, they may be diverted into two models.

\section{Pattern Model}

Here, there are four types of research introduction using patterns. Hartley (2008), Jogthong (2001), Jalilifar (2010), and Al Qahtani (2006) used CARS model as their barometer to measure the research article introductions. CARS model has been used by many people up to now because it is applicable and rationale. Therefore, they mostly used this model to organize their RAls. Then, Adnan (2011) used CARS and PJP to analyze the Indonesian RAls, specifically in the introduction section. Writing research article introductions using CARS model dominated in their generic structures. Some said because it has high influences in the study of RAls. Those are modified to be IPS model in organizing the RAls.

Then, Adnan (2011), offered an IPS model as a pattern to organize the generic structures in the RAls. In his model, there are three moves in which each move has strategy choices (as stated 'or'). It means that not all the strategies should be applied in RAls. Therefore, the generic structure used in this model is not really monotonously applied. It is not used only one or some styles as those presented, but it can be used depending on their context and situations.

Slatcher \& Pennebaker as cited by Hartley $(2008 ; 42)$ has three stages that in the first one has 2 paragraphs describing research areas. It directs to the points of the research. Second stage is stating the previous literatures and then finding the gab. The last stage is writing short conclusion and then place the gab as the aims of the study.

Quotation can be directly applied in the beginning of the introduction, based on Ball and Vincent at cited by Wood (1999). The strategies used in the Ball and Vincent in writing research introduction are to contrast and compare the ideas in how the way they organize contents, generic structures and the function. Then, how other writers analyzed the data are also the subjects of comparing strategies. The last paragraph of research introduction is conclusion about all the comparisons and what the study about.

\section{Free models}

In free models, there 2 experts who said that there is no permanent and it tends to the writers' creativities. One of the free models applied by Tulu (2009) who also said that the RAls can be begun by strictly to the points, the statements should be clearly presented, the information in the RAls is greater as the reader needs, and the last and important thing knows the reviewers' interests. It tends to the free styles of RAls in term of generic structures, but it looks focusing on the journal publications. 
In addition to free models, according to Kalandadze (2007) similar to Tulu, there is no any permanent model. It depends on the creativities of the writer. To inform the backgrounds, she tends more on what context the writing and what the model is. She furthermore said that at least there are eight elements involved in the introduction of research, such as stating the problems, research areas, the reasons of conducting research, the variables, hypothesis, and research scopes.

The pattern models above show us that RAls in research papers really needs a pattern to consistently written. In other hand, some guidelines as the author showed that there is no any certain pattern offered by a reviewer or scientific journal in the introduction section. For some cases, many also submitted articles have been unpublished internationally. It may be caused by their introduction or may be their other parts. However, it can be rationally though that as long as the RAls appropriate with the guide-lines, not using patterns, it is receivable. Also in other sides, we may think that as long as the pattern makes us easier writing RAls and doesn't change its essentials delivery contents, the pattern models also can be applied in our writings. Moreover, it can surely help us to follow their steps better than we have nothing to follow. As proof, many articles applying these patterns can be internationally published.

\section{Conclusion}

Those two models stated that we need to understand on how the generic structures of RAls applied in particular journal articles. The guidelines from the journal need more attention before going to publish your research articles. If there is no any instruction for the introduction sect-ions, choice of generic structure may come to you depending on what you comfortable for, and what the strategies you apply. For this study, the RA introductions using pattern models are more acceptable than they in the free models. It related to those who analyze many RAls for many times. Therefore, if the journal, which you direct to publish your articles, doesn't have pattern, you are recommended to apply the patterns as the following: CARS model from Swales, IPS model from Adnan (2011), Slatcher \& Pennebaker, and Ball \& Vincent.

\section{References}

Adnan, Z. (2011). Ideal-Problem-Solution (IPS) Model; Discourse Model of Research Article Introductions (RAls) in Education. (71-103).

Al-Qahtani, A. (2006). A Contrastive Rhetoric Study of Arabic and English Research Article Introductions. Submitted to the Oklahoma State University.

Hartley, J. (2008). Academic Writing \& Publishing. A Practical Handbooks. NY: Routledge

Jalilifar, A. (2010). Research Article Introductions: Sub-disciplinary Variations in Applied Linguistics. The Journal of Teaching Language Skills, 2(2), Page 30-55

Jogthong, C. (2001). Research Article Introductions in Thai: Genre Analysis of Academic Writing. Research for doctoral program. Morgontown, Virginia.

Kalandadze, M. (2007). English academic writing. Tbilisi, 0108, 10 T. Chovelidze Street. Central European University, Budapest 
Pasongli, N. (2016). The Cultural Analysis of Ma'pasilaga Tedong in Rambu' Solo Ceremony in Tana Toraja Regency. Skripsi. Universitas Islam Makassar

Tulu, I.T. (2009). Research Methods, Guidelines and Formats. Adama University. Adama, Ethiopia.

Van De Weghe, R. (2007). Research Matters. English Journal, 97(1). pp. 101-104.

Warsidi. (2013). A Collaboration of Mind Mapping and Organizational Pattern to Improve Students' Essay Writing Ability. http://pasca.unhas.ac.id/jurnal/\#vol

Woods, P. (1999). Successful writing for qualitative researchers. London \& New York: Routledge. 